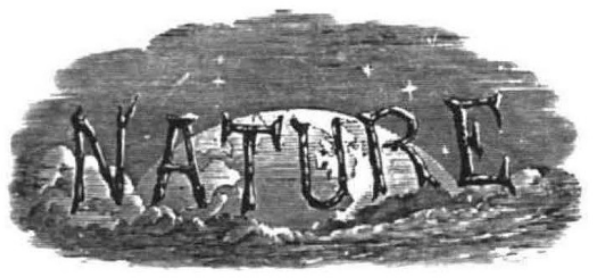

SATURDAY, SEPTEMBER 24, I932

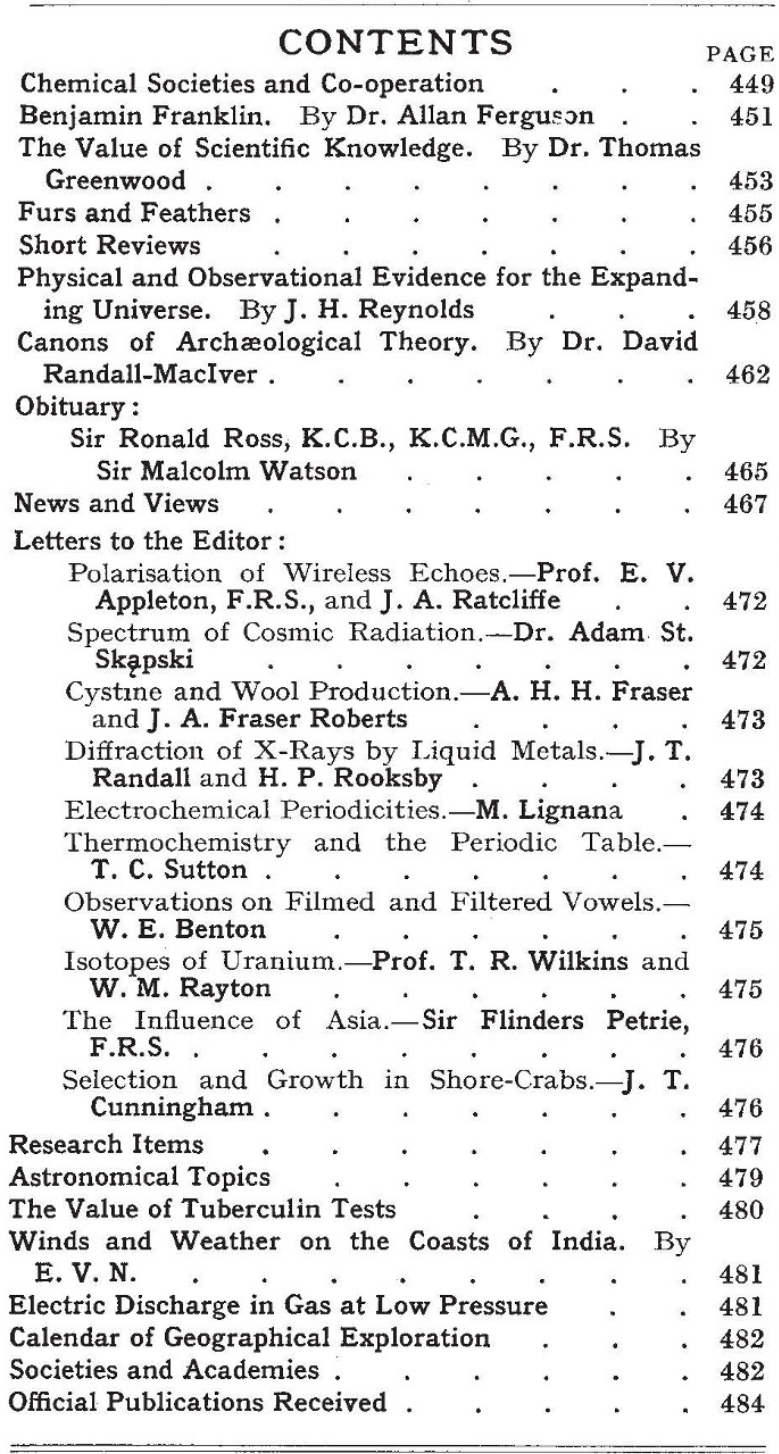

Editorial and Publishing Offices:

MACMILLAN \& CO., LTD.

ST. MARTIN'S STREET, LONDON, W.C. 2

Telephone Number: WHITEHALL 8831

Telegraphic Address: PHUSIS, LESQUARE, LONDON

Advertisements should be addressed to

T. G. Scott $E$ Son, Ltd., 63 Ludgate Hill, London, E.C. 4

Telephone Number: City 1266

No. 3282, VoL. 130]

\section{Chemical Societies and Co-operation}

THE industrial complexion of the present-day world, with its political and financial complications, has of necessity led numerous institutions concerned with the production and distribution of commodities, and with means to assess and exchange their value, to abandon convenient and traditional procedure and to discover alternatives which have the merit, under the new conditions, of combining self-preservation with the supply of the public needs. The science of chemistry has been harnessed to the industrial machine with a rapidity which appeared unlikely twenty years ago, and its record of service is already such as to presage the extension, as quickly as the difficulties of the moment permit, of this collaboration.

Responsibility for promoting such co-operation is shared by the Government and other public bodies, by industrialists, and by the chemical profession itself ; but whilst the acquisition of chemical knowledge is a task shared directly or indirectly by all of these, its distribution is a burden which is borne almost entirely by the producers themselves. Hence many institutions devoted to the extension of scientific knowledge are faced with the same problems as the interests to the assistance of which they have been summoned. They have now to consider afresh how they can best realise their increasing responsibilities towards the national needs, while at the same time finding means to guard against serious deterioration of their distributing organisation.

Chemical societies, in common with other scientific bodies, are not greatly-if at all-concerned with questions of professional rewards, for the care of which provision is made by appropriate professional organisations. They acknowledge that it is one of their duties to promote scientific intercourse among their members, and to make such provision as may be deemed necessary to facilitate research and its discussion; but the principal duty which is laid upon them by common consent as well as by the force of circumstances is to publish to the world the records of original investigation, to do so as far as is possible without any restriction other than the scientific value of the material, and to prepare and distribute summaries of current researches in a world-wide or limited field.

This twofold publication is the very foundation of all new knowledge, and the disastrous effect of any appreciable curtailment - apart from such devices for abbreviation as may be easily intelligible to workers in the science-is only too fully realised. Consequently, much serious consideration has of 
late been given to the possibility of reorganisation, co-operation, federation, and unification of the various societies devoted primarily or exclusively to promoting advance in chemical knowledge. It is, for example, scarcely fortuitous that Prof. G. T. Morgan dealt at some length with the subject in his presidential address to the Society of Chemical Industry in July, and that Prof. G. G. Henderson's presidential address to the Chemical Society in March also referred to the matter; neither were Prof. J. F. Thorpe's observations in his presidential addresses to the Chemical Society in 1930 and 1931 intended for the consideration only of fellows of that Society. Indeed, although these two chemical societies have properly taken the lead in the examination of the position and in the suggestion of methods whereby present difficulties may be surmounted and future progress assured, the problem is one which vitally concerns every chemical association and every research laboratory in the British Commonwealth.

Naturally enough, delicate and complex considerations arise with every suggestion of reunion or federation-two methods whereby considerable economy in administrative costs without contraction in scientific services might be anticipated-but encouragement is to be found in the manner in which these difficulties are being examined and discussed. Moreover, confidence arises from the fact that, for the past eight years, a substantial measure of joint operation has been successfully achieved in connexion with the publication of abstracts of chemical literature. It is well known that, by the establishment in 1924 of the Bureau of Chemical Abstracts, a body composed of representatives of the Chemical Society and the Society of Chemical Industry and charged with the production of a comprehensive and world-wide survey of current researches in both pure and applied chemistry, substantial economies have been rendered possible, while at the same time the ever expanding literature of the science is summarised and indexed with commendable accuracy, promptitude, and completeness. There can be few among those conversant with the work of this undertaking, with the needs of research workers both in academic and in industrial laboratories, and with the moderate financial resources at the command of the two societies, who would not declare this experiment in co-operative enterprise to be an unqualified success ; indeed, we are unaware of any suggestion having been made that the older procedure, with its inherent lack of co-ordination and inevitable duplication, should be resumed. Few, too, would contest the desirability, in general, of a wider measure of co-operation in which other societies would participate, in order that efficiency might go hand in hand with elasticity and stability, and that the financial clouds which obscure clear vision of the future and cause anxiety for the continued supremacy of British Chemical Abstracts might be dissipated once and for all.

In his address Prof. Morgan quoted some pertinent facts and equally instructive figures; even if we admit that the exact significance of both depends on the point of view, we are still constrained to point out the inequity of so severe a task-albeit but part of the whole duty of publication-being left on the shoulders of two out of perhaps sixteen societies which are devoted to the furtherance of chemistry in one or other of its branches. Earlier this year Prof. Henderson referred to this circumstance with commendable frankness. "On these two societies alone", he said, "falls the financial burden of this great work, work which is for the benefit of every chemist in the country. It is singular and anomalous that hundreds, perhaps even thousands, of professional chemists exist here, who make no contribution to this burden, who do nothing to help the cause of chemistry in the way that is most urgent, most necessary, and most expensive." Likewise Prof. Thorpe in 1031 said: "The burden of publication now falls almost exclusively on the Chemical Society and the Society of Chemical Industry, and although it is probably correct to assume that the Journals of these Societies are of interest chiefly to their members, such an assumption cannot be made in the case of the $\mathrm{Ab}$ stracts, which ought to be of interest to all chemists, and ought to be supported by all chemists." Indeed, we would go even further and submit that the fundamental importance of chemistry to our national prosperity lays upon the State itself the duty of rendering timely assistance in this matter.

We come, therefore, to the following conclusions: First, that the present financial circumstances of the chemical societies of Great Britain demand either curtailment of services to chemists of all descriptions, or some countervailing form of retrenchment. Second, that the reduction in administrative expenses which in the course of time would follow unification or some form of very close association would assist in removing these financial difficulties, and would at the same time promote solidarity and efficiency. Third, that a substantial experiment in joint publication has proved successful over a considerable period. Fourth, that the cost of, and responsibility for, certain 
essential activities ought to be shared more widely. Taken together, they present an almost unanswerable case for amalgamation or federation, although of course they do not indicate exactly how it is to be achieved. As Prof. Morgan has pointed out, advocates of reunion have to face the fact that certain kindred societies have a mixed membership, consisting only partly of chemists; yet this has not deterred the Faraday Society and the Chemical Society from entering into conversations with the view of undertaking joint publication representative of physical chemistry in Great Britain. It has also been suggested that the news section of $C h e m$ istry and Industry should be published by a combination of the main chemical associations, and should be "an outward and visible sign of the reunion to which many of us aspire". "Is it not high time ", asked Prof. Morgan, " that we evolved a considerable chemical organisation with a comprehensive chemical journal worthy of that community of nations known as the British Empire?"

Many of us, while not pretending that geographical boundaries can circumscribe the sciences, feel strongly that the national consciousness of British scientific achievement might with advantage be stimulated in this way and by other like means. "Chemistry House", which would have commanded public interest, was conceived as a means whereby the various societies representing chemistry and allied subjects might be brought into close physical association, so that certain activities, such as the library and a bureau of information, might be conducted jointly. Unfortunately, the project was born into a world of financial, political, and economic unrest, which soon became a panic, and the scheme must now submit to rebirth in less troublous times. Here again is a plan which carries with it the certainty of eventual economic advantage combined with that increase in effective service which cannot fail to accompany centralisation and the multiplication of opportunities for co-operation, if indeed it does not lead to the actual regrouping of chemical societies in larger units.

It ought not to be impossible by other methods, however, to secure a substantial part of the economies adumbrated by the " Chemistry House" scheme, and to do so relatively cheaply and without pressing the thorny questions of amalgamation or autonomy to an immediate decision. With this aim Sir William Pope, in a communication to Chemistry and Industry, recently proposed that Mr. E. R. Bolton, Dr. L. H. Lampitt, Prof. G. T. Morgan, Prof. J. C. Philip, Mr. J. Davidson Pratt, Dr. F. L. Pyman, and Mr. W. Rintoul, as repreNo. 3282 , VoL. 130] senting the principal societies concerned, should be asked to constitute a committee which would consider how the resources of the various bodies concerned with the professional and scientific welfare of chemists can be most economically and efficiently utilised. If, for example, administration could be concentrated under one head in one building, the Chemical Society's library and rooms at Burlington House continuing to be the chief centre of scientific and technical activity, substantial mutual advantage would doubtless result.

But why, it may be asked, should these considerations of unity or separation, of co-ordination or non-co-operation, of economy or stringency, be regarded as matters of interest to citizens outside the ranks of the chemical profession? Why, we might reply, were the conversations at Ottawa of interest to others besides professional politicians and economic theorists? At least they have this in common: that the science of chemistry and the science of government, each depending for its operation and extension on a highly trained 'civil service' and on adequate and accurate information, are both deeply concerned with the resources of the British Empire and with the use that we and our fellow-subjects overseas can make of them "The time is ripe", Prof. Morgan said, "for a systematic study of the material resources of the British Empire, and this task is mainly a chemist's job. Many of the natural products of the Dominions and Dependencies are in need of intensive chemical investigation. To carry out such researches in a thoroughly effective and compre hensive manner needs the expert organisation which could be best supplied by a central body fully representative of British chemistry. Every branch of chemical science would have an essentia part to play in this great undertaking."

\section{Benjamin Franklin}

The Ingenious Dr. Franklin: Selected Scientific Letters of Benjamin Franklin. Edited by Nathan G. Goodman. Pp. xi +244 . (Philadelphia : University of Pennsylvania Press ; London : Oxford University Press, 1931.) 15s. net.

CENTENARIES are fashionable nowadays, and $\cup$ certainly the bicentenary of the Philadelphia Library is a day to be marked with a white stone. Franklin's restless and versatile mind was ever occupied with schemes for human betterment, and one of the most beneficial of his many beneficent deeds is perpetuated in the inscription telling us that ". . the Philadelphia Youth [then chiefly 